\title{
Aplikasi Asuhan Keperawatan Psikososisal Pada Ny. D Dengan Masalah Ketidakberdayaan
}

\author{
Juliana Simanjuntak \\ julianasimanjuntak595@gmail.com
}

\section{BAB 1}

\section{PENDAHULUAN}

\subsection{Latar Belakang}

Diabetes Melitus (DM) merupakan penyakit metabolik dengan ciri kadar gula darah yang tinggi. DM tipe 2 paling sering diderita. Penyebabnya karena pola hidup yang tidak sehat,beberapa upaya untuk mengurangin faktor pemicu seperti mengatur pola makan,kontrol berat badan,berolahraga,pantau gula darah,diet yang terarah,gizi sehat dan seimbang. Selain itu,dukungan keluarga juga mempengaruhi kualitas hidup pasien DM (Saviqoh, Hasneli \& Nopriadi, 2021).

Diabetes Melitus merupakan kondisi kronis yang ditandai dengan peningkatan kosentrasi glukosa dalam darah disertai urine yang mengandung glukosa. Salah satu tipe dari dibaetes melitus adalah tipe 2 atau non insuline dependent diabetes melitus. Pasien dengan kondisi diabetes melitus tipe 2 harus menjalani pengobatan agar kondisi gula darahnya tetap stabil. keberhasilan pengobatan pasien dipengaruhi oleh relugasi diri yang dimiliki oleh pasien (Sari \& Simanjuntak,2020). Berdasarkan hasil riskesdes pada tahun 2018 angka terjadinya diabetes melitus pada usia 15 tahun keatas yakini indonesia $(6,9 \%)$. Beberapa diantaranya dengan presentasi cukup besar mempunyai penyakit diabetes melitus DKI jakarta $(3,8 \%)$, Aceh $(2,6 \%)$, Sumatera Utara $(2,3 \%)$.

Diabetes melitus mempunyai gejala yang mirip dan komplikasi pada tingkat lanjut. Bila seseorang terkena diabetes melitus tidak menerima perawatan secara rutin bisa menyebabkan beberapa komplikasi (Maruhashi \& Higashi, 
2021). Kompikasi dalam diabetes melitus mempunyai jangka waktu yang lebih lama termasuk kardiovaskuler, kerusakan retina menyebabkan kebutaan dan kerusakaan saraf yang bisa menyebabkan impontensi dengan resiko amputasi, Sehingga dampak yang akan terjadi pada penderita diabetes melitus akan muncul ketidakberdayaan (Regina,Mu'ti \& Fitriany, 2021).

Ketidakberdayaan merupakan dampak terbesar dari penyakit kronis sebagai hasil dari penerimaan diri dan perubahan gaya hidup klien dengan penyakit kronis (Ramadia, Keliat \& wardani, 2019).ketidakberdayaan merupakan perasaan kurang mampu mengendallikan lingkungannya yang membimbing pada sikap menyerah atau putus asa dan mengarahkan atribusi diri yang kuat bahwa dia memiliki ketidakmampuan (Prayogo \& Rehulina, 2015).

Ketidakberdayaan adalah pengalaman tentang kurangnya kontrol seseorang terhadap situasi termasuk persepsi bahwa sesuatu tidak akan bermakna mampu mempengaruhi terhadap hasil yang ingin dicapai, seseorang yang mengalami ketidakberdayaan kehilangan kontrol terhadap kejadian dalam hidupnya dan merasa segala sesuatu tidak bermakna bagi dirinya. Perasaan ketidakberdayaan disebabkan pengalaman distress dan perubahan emosional seperti agitasi, frustasi, marah, takut dan cemas. Perasaan ketidakberdayaan yang dialami oleh pasien stroke sering kali disertai depresi, Ketidakberdayaan pada pasien diabetes melitus muncul karena pasien cenderung bergantung pada orang lain (Nuraliyah \& Burmanajay, 2019). Berdasarkan uraian diatas maka penulis tertarik untuk mengambil kasus ketidakberdayaan pada penderita Diaabetes melitus di Bakti Luhur. Pertimbangan utama pengambilan kasus ini pada Ny. D karena pada kehidupan sehari-hari hanya berbaring ditempat tidur sehingga kondisi ketidakberdayaan akan memperburuk kondisi.

\subsection{Tujuan penulisan}

\section{Tujuan umum}

Untuk memberikan asuhan keperawatan pada Ny. D dengan masalah ketidakberdayaan 


\section{Tujuan khusus}

a. Mahasiswa mampu melakukan pengkajian pada Ny. D dengan masalah ketidakberdayaan

b. Mahasiswa mampu melaksanakan diagnosa pada Ny. D dengan masalah ketidakberdayaan

c. Mahasiswa mampu membuat intervensi pada Ny. D dengan masalah ketidakberdayaan

d. Mahasiswa mampu melakukan implementasi pada Ny. D dengan masalah ketidakberdayaan

e. Mahasiswa mampu membuat evaluasi pada Ny. D dengan masalah ketidakberdayaan 


\section{BAB 2}

\section{TINJAUAN TEORITIS}

\subsection{Konsep Ketidakberdayaan}

\subsubsection{Defenisi}

Ketidakberdayaan merupakan persepsi individu bahwa segala tindakan akan mendapatkan hasil atau suatu keadaan individu kurang dapat mengendalikan kondisi tertentu atau kegiatan yang baru dirasakan (Pardede,2020). Ketidakberdayaan merupakan persepsi atau tanggapan seseorang bahwa perilaku atau tindakan yang sudah dilakukan nya tidaknya akan membawa hasil yang diharapkan atau tidak akan membawa perubahan hasil seperti yang diharapkan, sehingga seseorang sulit mengendalikan situasi yang akan terjadi (wahyudi \& Burnamajaya, 2020).

Ketidakberdayaan merupakan kondisi seseorang yang merasa kurang mengontrol kejadian, pribadi, ataupun situasi yang memberi dampak pada pandangan tujuan dan gaya hidup (Yusuf \& Wardani, 2015). Ketidakberdayaan adalah pengalaman tentang kurangnya kontrol seseorang terhadap situasi persepsi bahwa sesuatu tidak akan bermakna mampu mempengaruhi terhadap hasil yang ingin dicapai (Jannah \& Putri,2015). Ketidakberdayaan dapat muncul akibat kebiasaan dimasa lampau dan perubahan kemampuan fisik akibat penyakit (Ummah, Wardani \& Hargiana 2018). Ketidakberdayaan adalah suatu kondisi dimana individu merasa tidak mampu menahan segala hal menyakitkan dan tidak nyaman yang dialami oleh dirinya sendiri (Azari \& zururi, 2020)

\subsubsection{Etiologi Ketidakberdayaan}

Etiologi ketidakberdayaan menurut (Tim Pokja SDKI DPP PPNI, 2017) antara lain :

1. Program pengobatan/perawatan yang mempunyai jangka panjang 
2. Lingkungan yang tidak mendukung dalam pengobatan/perawatan.

3. Interaksi interpersoanal yang tidak memuaskan

Ketidakberdayaan disebabkan karena kurangnya pengetahuan, ketidakadekuatan koping sebelumnya (seperti : Depresi), serta kurangnya kesempatan dalam membuat keputusan (Novi, 2017). Faktor yang berhubungan dengan ketidakberdayaan menurut (Novi, 2017) yaitu:

a. Kesehatan lingkungan : hilangnya privasidan kontrol terhadap terapi

b. Hubungan interpersonal : penyalahgunaan kekuasaan dan hubunganyang kasar.

c. Penyakit yang berhubungan dengan rejimen : penyakit kronis atau yang melemahkan kondisi. Hal tersebut menyebabkan seseorangtidak dapat melakukan kegiatan aktivitas fisik dan juga tidak mampu melaksanakan tanggung jawab serta menjalankan perannya.

\subsubsection{Patofisiologi Ketidakberdayaan}

Pada patafisiologi dengan masalah ketidakberdayaan saat ini belumdapat diketahui secara pasti, namun jika dilakukan analisis dari proses terjadinya ketidakberdayaan berasal dari seseorang individu yang tidak mampu mengatasi suatu masalah sehingga menyebabkan stress yang hal tersebut diawali dalam perubahan dalam respon otak yang menafsirkan perubahan didalam otak. Stress tersebut akan menyebabkan korteks serebri yang akan mengirimkan sinyal menuju hipotalamus, yang kemudian seharusnya ditangkap system limbic yang dimana salah satu bagian pentingnya merupakan amigdala itu akan bertanggung jawab didalam status emosional individu akibat dari keaktifan system hipotalamus pituitary adrenal (HPA) dan kemudian menyebabkan rusaknya pada hipotalamus menjadikan seseorang kehilangan mood dan juga motivasi dan akhirnya menyebabkan 
seseorang untuk malas melakukan sesuatu,hambatan emosional dengan klien yang mengalami ketidakberdayaan, terkadang dapat berubah menjadi murung dan sedih sehingga menyebabkan seseorang itu merasa tidak berguna lagi, dan merasa hidupnya telah gagal (Sarani, 2021)

\subsubsection{Kondisi Klinis Ketidakberdayaan}

Diagnosa yang tidak terduga atau baru, Peristiwa traumatis, Diagnosis penyakit kronis, Diagnosis penyakit terminal dan Rawat inap menurut SDKI (2018).

\subsubsection{Tanda dan Gejala}

1. Batasan kararakteristik SDKI :

a. Mayor

Subjektif : Menyatakan frustasi atau tidak mampu melaksanakan aktivitas sebelumnya

Objektif : Bergantung pada orang lain

b. minor :

Subjektif : Merasa diasingkan, Menyatakan keraguan tentang kinerja peran, Menyatakan kurang kontrol, Menyatakan rasa malu dan Merasa tertekan (depresi).

Objektif : Tidak berpartisipasi dalam perawatan dan Pengasingan

2. Batasan karakteristik klien dengan ketidakberdayaan. ketidakberdayaan yang dialami klien terdiri dari energi dan tingkatan yaitu:

a. Rendah Klien akan mengungkapkan ketidakpastian tentang fluktuasi tingkat energi dan bersikap positif.

b. Sedang Klien akan mengalami ketergantungan kepada orang lain yang dapat mengakibatkan ititabilitas, ketidaksukaan dan rasa bersalah. 
c. Berat Klien akan menunjukan sikap apatis, depresi terhadap perubahan dalam dirinya yang telah terjadi.

\subsubsection{Faktor Predisposisi}

Faktor predisposisi merupakan suatu faktor resiko yang menjadi sumber utama stress dan memiliki pengaruh dalam tipe dan sumber individu untuk menghadapi stess secara biologis, psikologis dan sosial budaya, Faktor predisposisi tersebut antara lain :

a. Biologis

1. Riwayat keturunan

2. Gaya hidup (Merokok, Alkohol dan zat adiktif)

3. Penderita penyakit kronis ( stroke, diabetes melitus)

4. Memeliki riwayat penyakit jantung paru-paru yang mengaktivitasnya sehari-hari klien.

5. Memiliki riwayat menderita penyakit secara progresif menimbulkan ketidakmampuan (Stroke, kanker terminal dan Aids)

b. Psikologis

1. Memiliki pengalaman perubahan didalam gaya hidup akibat lingkungan tempat tinggal

2. Ketidakmampuan dalam mengambil suatu keputusan serta mempunyai kempuan untuk melakukan komunikasi verbal yang kurang atau tidak mampu untuk mengekspresikan perasaan yang dirasakan terkait dengan penyakit atau kondisi yang sedang terjadi.

3. Tidak mampu menjalankan peran akibat suatu penyakit secara progresif menimpulkan ketidakmampuan ( stroke, kanker terminal dan AIDS).

4. Merasa kurang puas dengan kehidupan yang telah dijalani (merasatujuan hidupnya tidak tercapai).

5. Merasa frustasi dengan keadaan kesehatannya dengan kondisi yangbergantung dengan orang lain. 
6. Self control : sulit untuk mengontrol rasa emosi, merasa cemas, merasatakut, gaya hidup yang tidak berdaya

c. Social budaya

1. Pendidikan rendah.

2. Kurang aktif didalam kegiatan masyarakat.

3. Hilangnya kemampuan dalam melakukan aktivitas akibat proses penuaan (pension, defitit memori, defisit motoric dan status finansial)

4. Cenderung bergantung dengan orang lain, tidak dapat berpartisipasi dalam social kemasyarakat

\subsubsection{Faktor presipitasi}

Faktor presipitasi merupakan suatu kondisi internal seorang pasien dimana pasien tersebut kkurang dapat menerima perubahan fisiknya dan psikologis yang telah terjadi. Kondisi eksternal biasanya dari pihak keluarga dan masyarakat kurang mendukung (Sarani, 2021). Faktor-faktor lain yang berhubungan dengan faktor presipitasi yang akan timbul ketidakbaerdayaan antara lain :

a. Biologis

1. Seseorang menderita suatu penyakit dan harus melakukan tindakanterapi tertentu, pengobatan terkait dengan penyakit (jangka panjang, sulit dan kompleks).

2. Penyakit kronis yang kambuh dalam 6 bulan terakhir.

3. Kurang mampu menyusaikian diri dengan budaya, ras etnik dangender.

4. Adanya perubahan didalam diri (fisik).

b. Psikologis

1. Perubahan gaya hidup akaibat memiliki penyakit kronis.

2. Tidak dapat melakukan aktivitas sendiri kemudian timbullah keputusasaan. 
3. Perasaan malu serta rendah diri karena aktivitas bergantung dengan orang lain.

4. Kehilangan rasa mandiri atau ketergantungan dengan orang lain.

c. Social budaya

1. Kehilangan pekerjaan karena kondisi kesehatan sekarang.

2. Kehilangan kemampuan dalam melakukan aktivitas dari prosespenuaan (pensiun, defisit memori, defisit motoric dan status finansial).

3. Terdapat perubahan status kuratif menjadi status paliatif.

4. Tidak dapat melakukan kegiatan agama dan tidak mampu melakukanpartisipasi dengan masyarakat.

\subsection{Konsep Asuhan Keperawatan}

\subsubsection{Pengkajian}

Pengkajian adalah tahap awal dari sebuah proses keperawatan dan juga merupakan proses sistematis yang dilakukan untuk mengumpukan data dari berbagai sumber, yang digunakan untuk mengevaluasi dan mengidentifikasi status kesehatan seorang pasien. Pengkajian yang lengkap, akurat, sesuai dengan kejadian atau kenyataan kebenaran dalam data ini sangat diperlukan untuk merumuskan diagnosa keperawatan dan juga digunakan dalam pemberian pelayanan kesehatan sesuai dengan respon masingmasing individu yang kemudian telah ditentukan dalamstandar praktik keperawatan.

\section{Identitas Klien}

meliputi nama pasien nama yang bertanggung jawab, alamat, nomor register, agama, pendidikan, tanggal masuk rumah sakit dan diagnosa medis

\section{Keluhan utama}


Biasanya pasien menyatakan perasaan frustasi atau mengungkapkan bahwa dia tidak mampu melakukan aktivitas sehari-hari seperti sebelumnya layaknya orang yang sehat, pasien merasa sangat bergantung dengan orang yang lain (Tim Pokja SDKI DPP PPNI, 2017)

\section{Riwayat sekarang}
a. Riwayat kesehatan sekarang
b. Riwayat kesehatan dahulu
b. Riwayat kesehatan psikologi
c. Riwayat kesehatan keluarga

\subsubsection{Diagnosa Keperawatan}
a. ketidakberdayaan
b. kecemasan
c. Penampilan tidak efektif

\subsubsection{Intervensi Ketidakberdayaan}

1. Tujuan Intervensi Keperawatan

a. Tujuan Umum: Klien Menunjukkan kepercayaan kesehatan dengan criteria: merasa mampu melakukan, merasa dapat mengendalikan dan merasakan ada sumber-sumber

b. Tujuan Khusus : Klien menunjukkan partisipasi: keputusan perawatan kesehatan ditandai dengan

1. Mengungkapkan dengan kata-kata tentang segala perasaan ketidakberdayaan.

2. Mengidentifikasi tindakan yang berada dalam kendalinya

3. menghubungkan tidak adanya penghalang untuk bertindak

4. Mengungkapkan dengan kata-kata kemampuan untuk melakukan tindakan yang diperlukan 
5. Melaporkan dukungan yang adekuat dari oramg terdekat, termasuk teman dan tetangga

6. Melaporkan waktu, keuangan pribadi dan ansuransi kesehatan yang memadai

7. Melaporkan ketersediaan alat, bahan, pelayanan dan transportasi

\section{Rencana Tindakan}

a. Bantu pasien untuk mengidentifikasi factor-faktor yang dapat berpengaruh pada ketidakberdayaan (misalnya: pekerjaan, aktivitas hiburan, tanggung jawab peran, hubungan antar pribadi).

Rasional: mengidentifikasi situasi/hal-hal yang berpotensi dapat dikendalikan dan dapat digunakan sebagai sumber kekuatan/power bagi klien.

b. Diskusikan dengan pasien pilihan yang realistis dalam perawatan, berikan penjelasan untuk pilihan tersebut.

Rasional: Memberikan kesempatan pada klien untuk berperan dalam proses perawatan, termasuk untuk meningkatkan pemikiran positif klien, dan meningkatkan tanggung jawab klien.

c. Libatkan pasien dalam pembuatan keputusan tentang rutinitas perawatan/rencana terapi

Rasional: Pelibatan klien dalam proses pembuatan keputusan, mampu meningkatkan rasa percaya diri.

d. Jelaskan alasan setiap perubahan perencanaan perawatan kepada pasien (jelaskan semua prosedur, peraturan dan pilihan untuk pasien, berikan waktu untuk menjawab pertanyaan dan minta individu untuk menuliskan pertanyaan sehingga tidak terlupakan) 
Rasional: Meningkatkan kemampuan berpikir positif terhadap proses perawatan yang sedang dijalani oleh klien, pelibatan klien dalam setiap pengambilan keputusan menjadi hal penting.

e. Bantu pasien mengidentifikasi situasi kehidupannya yang dapat dikendalikan (perasaan cemas, gelisah, ketakutan).

Rasional: Kondisi emosi pasien mengganggu kemampuannya untuk memecahkan masalah. Bantuan diperlukan agar dapat menyadari secara akurat keuntungan dan konsekuensi dari alternative yang ada.

f. Bantu klien mengidentifikasi situasi kehidupan yang tidak dapat ia kendalikan (adiksi), Disukusikan dan ajarkan cara melakukan manipulasi menghadapi kondisikondisi yang sulit dikendalikan, misalnya afirmasi.

Rasional: Dorong pasien untuk mengungkapkan perasaan yang berhubungan dengan ketidakmampuan sebagai upaya mengatasi masalah yang tidak terselesaikan dan menerima hal-hal yang tidak dapat diubah.

g. Bantu pasien mengidentifikasi faktor pendukung, kekuatankekuatan diri (misalnya kekuat an baik itu berasal dari diri sendiri, keluarga, orang terdekat, atau teman).

Rasional: Pada pasien dengan ketidakberdayaan dibutuhkan faktor pendukung yang mampu mensupport pasien, dari dalam sendiri dapat berupa penguatan nilai-nilai spiritual, Jika dalam proses perawatan kekuatan lain tidak adekuat.

h. Sampaikan kepercayaan diri terhadap kemampuan pasien untuk menangani keadaan dan sampaikan perubahan positif dan kemajuan yang dialami pasien setiap hari.

Rasional: Meningkatkan rasa percaya diri terhadap kemampuan atas upaya dan usaha yang sudah dilakukan oleh klien.

i. Biarkan pasien mengemban tanggung jawab sebanyak mungkin atas praktik perawatan dirinya. Dorong kemandirian pasien, tetapi bantu pasien jika tidak dapat melakukannya. 
Rasional: memberikan pilihan kepada pasien akan meningkatkan perasaannya dalam mengendalikan hidupnya.

j. Berikan umpan balik positif untuk keputusan yang telah dibuatnya.

\subsubsection{Implementasi}

Implementasi merupakan suatu tahap pelaksanaan terhadap suatu rencana tindakan keperawatan yang telah ditetapkan untuk perawat bersama seorang pasien. Implementasi dapat dilakukan sesuai dengan rencana yang telah dibuat setelah validasi, selain itu juga dibutuhkan keterampilan interpersonal, intelektual, dan tehnik yang dilakukan harus dengan cermat serta efisien dengan sitiasi yang tepat dan dengan selalu memperhatikan keamanan fisik maupun psikologis. Setelah sudah selesai melakukan implementasi, lakukan dokumentasi yang akan meliputi intervensi yang sebelumnya sudah dilakukan dan tanyakan bagaimana respon pasien (Sarani, 2021)

\subsubsection{Evaluasi}

Evaluasi merupakan tahap terakhir dalam proses keperawatan. Evaluasi ini adalah kegiatan membandingkan hasil yang telah dicapai setelah dilakukan implementasi keperawatan dan memiliki tujuan yang diharapakan dalam perencanaan. Perawat pun mempunyai tiga alternative dalam menetukan sejauh mana tujuan itu dapat tercapai :

1. Berhasil : perilaku pasien sesuai dengan pertanyaan tujuan dalam waktu dan tujuan yang telah ditetapkan. Tercapai sebagian : pasien telah menunjukan perilaku tetapi belum sebaik dengan perilaku yang telah ditentukan dalam pertanyaan tujuan.

2. Belum tercapai : pasien belum mampu sama sekali menunjukkan perilaku yang telah diharapkan sesuai dengan pernyataan tujuan (Sarani, 2021). Agar memudahkan perawat dalam mengevaluasi 
atau membuat perkembangan pasien maka digunakan komponen SOAP yaitu :

S : Data subyektif Merupakan perkembangan suatu keadaan pasien yang didasarkan pada apa yang telah dirasakan, dikeluhkan dan yang diungkapkan.

O : Data obyektif Merupakan perkembangan yang dapat diamati dan juga dapat diukur oleh seorang perawat atau tim kesehatan yang lainnya

A : Analisis Merupakan penelitian dari kedua jenis data tersebut baik data subjektif maupun data objektif, apakah berkembang dengan baikatau malah kemunduran.

$\mathrm{P}$ : PerencanaanMerupakan rencana dalam penanganan pasien yang didasari pada hasil analisis diatas yang mempunyai isi untuk melanjutkan perencanaan apabila masalah belum teratasi 


\section{BAB 3}

\section{TINJAUN KASUS}

\subsection{Pengkajian Keperawatan}

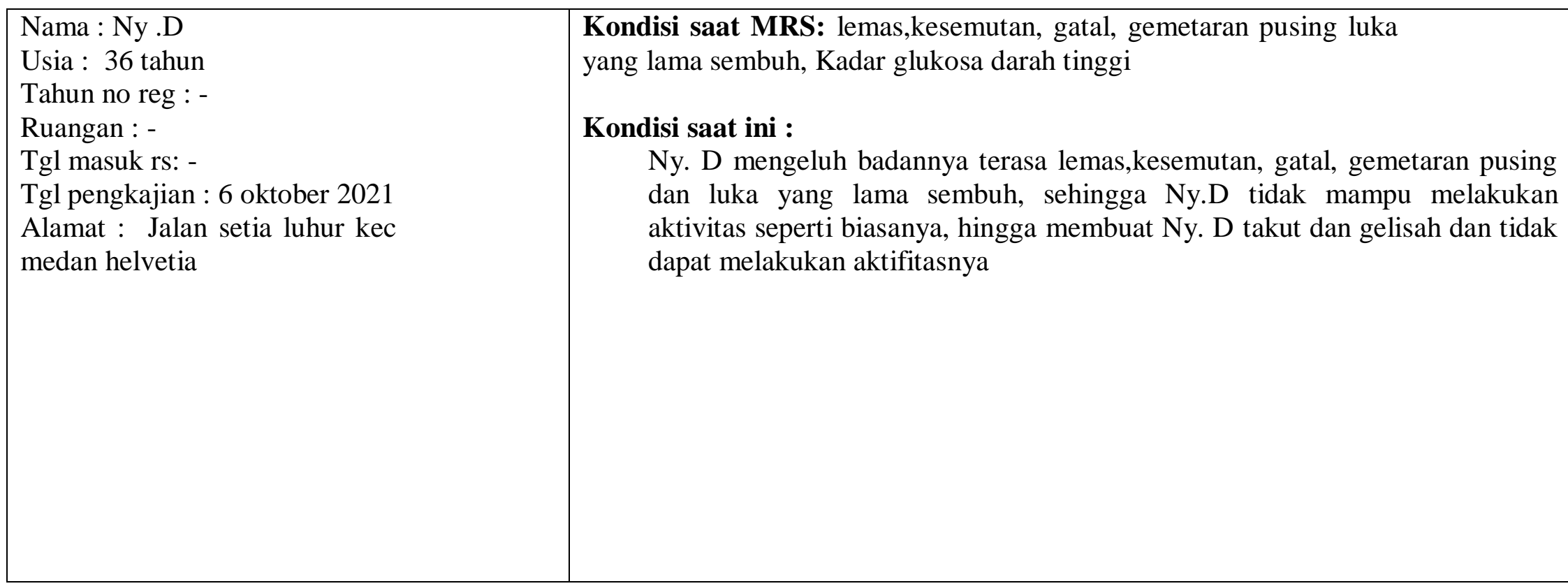


3.1.1 Faktor Predisposisi Dan Faktor Presipitasi

\begin{tabular}{|c|c|c|c|c|}
\hline \multirow[t]{2}{*}{ Faktor predisposisi } & \multicolumn{3}{|c|}{ Faktor Presipitasi } & \multirow[t]{2}{*}{ STRESSOR } \\
\hline & Nature & Origin & $\begin{array}{l}\text { Number \& } \\
\text { Timing }\end{array}$ & \\
\hline $\begin{array}{l}\text { Biologis: } \\
\text { 1. Diabetes melitus } \\
\text { 2. Ny. D menderita diabetes menderita diabetes melitus } \\
3 \text { tahun yang lalu } \\
\text { 3. Ny. D sering mengkonsumsi makanan manis } \\
\text { 4. Ny. D tidak rutin check up kepelayanan kesehatan }\end{array}$ & 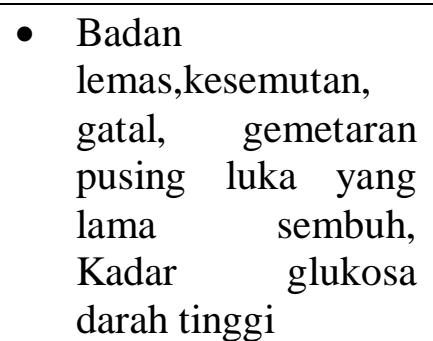 & Internal & $\begin{array}{lr}\text { Sejak } & 2 \\
\text { minggu } & \text { yang } \\
\text { lalu } & \end{array}$ & - Diabetes melitus \\
\hline $\begin{array}{l}\text { Psikologis : } \\
\text { 1. Ny. D memiliki kepribadian yang terbuka setiap ada } \\
\text { masalah akan dibicarakan dengan suaminya } \\
\text { 2. Ny. D merasa gemetaran, luka lama sembuh dan } \\
\text { juntung berdebar kencang } \\
\text { 3. Ny. D merasa cemas, takut gelisah dan panikan jika } \\
\text { memikirkan penyakitnya }\end{array}$ & $\begin{array}{l}\text { malu,kecewaTakut, } \\
\text { gelisah,jantung } \\
\text { berdebar,gemetran } \\
\text { - Sering kepikiran } \\
\text { penyakitnya }\end{array}$ & Internal & $\begin{array}{lr}\text { Sejak } & 2 \\
\text { minggu } & \text { yang } \\
\text { lalu } & \end{array}$ & $\begin{array}{ll}\text { - } & \text { malu takut } \\
\text { panikan, kwatir }\end{array}$ \\
\hline $\begin{array}{l}\text { Sosiocultural : } \\
\text { 1. Ny. D seorang perempuan umur } 36 \text { tahun } \\
\text { 2. Ny. D menikah dan memiliki } 2 \text { orang anak } \\
\text { 3. Ny.D merupakan ibu rumah tangga } \\
\text { 4. Sebelumnya Ny.D aktif terlibat dalam kegiatan } \\
\text { dilingkungan tempat tinggal seperti perwiritan atau } \\
\text { pengajian }\end{array}$ & $\begin{array}{l}\text { Malu dan kecewa } \\
\text { karena tidak bisa } \\
\text { bersosial mengikuti } \\
\text { kegiatan lingkungan } \\
\text { tempat tinggalnya }\end{array}$ & Eksternal & $\begin{array}{lr}\text { Sejak } & 2 \\
\text { minggu } & \text { yang } \\
\text { lalu } & \end{array}$ & Cemas \\
\hline
\end{tabular}




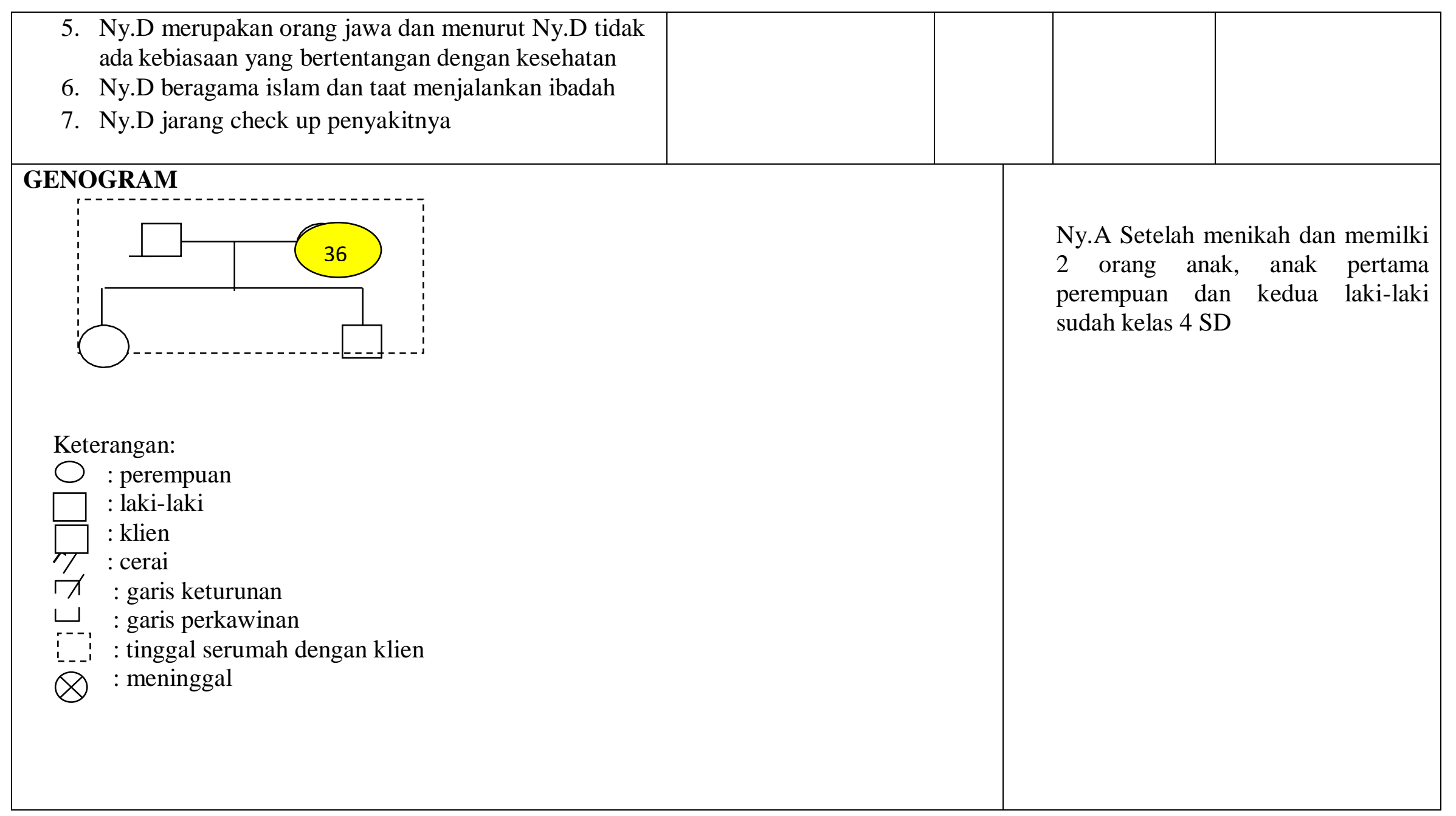




\subsubsection{Penilaian (Respon)Terhadap Stressor}

\begin{tabular}{|c|c|c|c|c|c|c|}
\hline STRESSOR & KOGNITIF & AFEKTIF & FISIOLOGIS & PERILAKU & SOSIAL & $\begin{array}{l}\text { DIAGNOSA } \\
\text { KEPERAWATAN }\end{array}$ \\
\hline $\begin{array}{l}\text { BIOLOGIS } \\
\text { (Diabetes } \\
\text { melitus) }\end{array}$ & 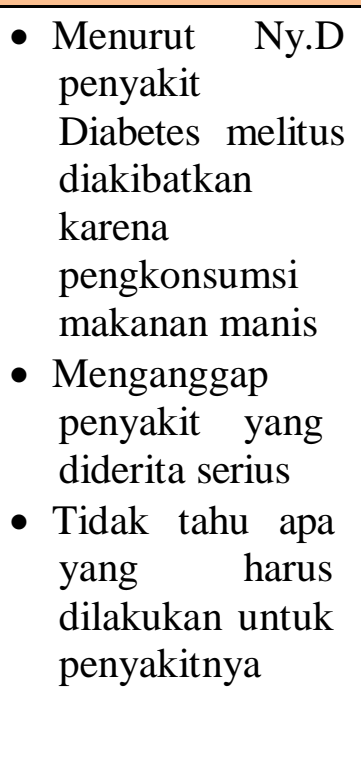 & $\begin{array}{l}\text { - } \text { Ny.D merasa } \\
\text { sedih dan } \\
\text { bingung } \\
\text { dengan } \\
\text { kondisi } \\
\text { penyakitnya }\end{array}$ & \begin{tabular}{|l} 
- Pusing \\
- Tulit tidur \\
makan nafsu \\
- Ny.D tampak \\
lemas \\
- Pemeriksaan \\
TTV \\
TD: $150 / 90$ \\
mmhg \\
N : 88 x / menit \\
P : $22 \mathrm{x} /$ menit \\
S: $37{ }^{0} \mathrm{C}$ \\
Kgd sewaktu : 200 \\
mg/dl
\end{tabular} & $\begin{array}{l}\text { - } \text { Ny.D } \\
\text { jarang } \\
\text { kontrol ke } \\
\text { rumah sakit } \\
\text { - Ekspresi } \\
\text { muka lesu } \\
\text { - Ny.Dtampak } \\
\text { lemasdan } \\
\text { gemetaran } \\
\end{array}$ & $\begin{array}{l}\text { - Pasien } \\
\text { mendatangi } \\
\text { dan } \\
\text { menggunakan } \\
\text { fasilitas } \\
\text { kesehatan yang } \\
\text { ada untuk } \\
\text { mencari } \\
\text { kesembuhan } \\
\text { terhadap } \\
\text { masalah yang } \\
\text { dihadapi saat } \\
\text { ini }\end{array}$ & - Ketidakberdayaan \\
\hline PSIKOLOGIS & $\begin{array}{l}\text { - Ny.D tidak tahu } \\
\text { bahwa }\end{array}$ & $\begin{array}{l}\text { - Merasa kesal } \\
\text { dengan }\end{array}$ & - Pusing & $\begin{array}{l}\text { - } \text { Tampak } \\
\text { cemas dan }\end{array}$ & $\begin{array}{l}\text { - Hubungan } \\
\text { Ny.Ddengan }\end{array}$ & - Ansietas \\
\hline
\end{tabular}




\begin{tabular}{|c|c|c|c|c|c|c|}
\hline $\begin{array}{l}\text { - sedih, cemas, } \\
\text { kesal dan } \\
\text { Bingung } \\
\text { dengan kondisi } \\
\text { penyakit dan } \\
\text { pengobatan } \\
\text { serta } \\
\text { Perawatannya }\end{array}$ & $\begin{array}{l}\text { badannya } \\
\text { menjadi lemah, } \\
\text { gemetaran dan } \\
\text { luka yang lama } \\
\text { sembuh } \\
\text { merupakan } \\
\text { dampak dari } \\
\text { penyakit yang } \\
\text { diderita } \\
\text { - Ny.D mengaku } \\
\text { bosan di rumah } \\
\text { sakit } \\
\text { Ny.D tidak tahu } \\
\text { pengobatan } \\
\text { seperti apa lagi } \\
\text { yang dapat } \\
\text { dilakukan untuk } \\
\text { mengobati } \\
\text { penyakitnya }\end{array}$ & $\begin{array}{l}\text { penyakitnya } \\
\text { yang tidak } \\
\text { sembuh- } \\
\text { sembuh }\end{array}$ & $\begin{array}{l}\text { - Mual } \\
\text { - Sulit tidur dan } \\
\text { sering } \\
\text { terbangun } \\
\text { apabila tidur } \\
\text { - Bahu terasa } \\
\text { tegang } \\
\text { - Tidak nafsu } \\
\text { makan } \\
\text { - Ny.D tampak } \\
\text { lemas } \\
\text { - Wajah Ny.D } \\
\text { tampak lemas } \\
\text { - Wajah Ny. D } \\
\text { tampak pucat } \\
\text { - Pemeriksaan } \\
\text { TTV } \\
\text { TD: } 150 / 90 \\
\text { mmhg } \\
\mathrm{N}: 88 \mathrm{x} / \mathrm{menit} \\
\mathrm{P}: 20 \mathrm{x} / \mathrm{menit} \\
\mathrm{S}: 366_{\mathrm{C}} \\
\mathrm{Kgd} \mathrm{sewaktu} \\
200 \mathrm{mg} / \mathrm{dl}\end{array}$ & $\begin{array}{l}\text { tidak } \\
\text { tenang } \\
\text { - Kadang } \\
\text { Ny.D } \\
\text { tampak } \\
\text { murung } \\
\text { - Ny.D } \\
\text { tampak } \\
\text { gelisah } \\
\text { - Ny.D } \\
\text { tampak } \\
\text { pasif dalam } \\
\text { menerima } \\
\text { perawatan } \\
\text { Ny.D } \\
\text { menunduk } \\
\text { saat bercerita }\end{array}$ & $\begin{array}{l}\text { suami baik } \\
\text { - Ny.D kurang } \\
\text { bersosialisasi } \\
\text { dengan } \\
\text { keluarga } \\
\text { Ny.D tetap } \\
\text { mengikuti } \\
\text { program } \\
\text { pengobatan } \\
\text { yang diberikan } \\
\text { kepadanya } \\
\text { akan tetapi } \\
\text { sikap Ny.D } \\
\text { pasif dalam } \\
\text { menerima } \\
\text { perawatan }\end{array}$ & $\begin{array}{l}\text { Kurang } \\
\text { pengetahuan }\end{array}$ \\
\hline
\end{tabular}




\begin{tabular}{|c|c|c|c|c|c|c|}
\hline $\begin{array}{l}\quad \text { SOSIAL } \\
\text { BUDAYA } \\
\text { - Sering } \\
\text { Memikirkan } \\
\text { anak-anak } \\
\text { yang masih } \\
\text { Yang jauh dari } \\
\text { rumah merasa } \\
\text { kasihan kepada } \\
\text { suami yang } \\
\text { harus menjaga } \\
\text { dan } \\
\text { merawatnya } \\
\text { setiap hari. }\end{array}$ & $\begin{array}{l}\text { - Ny.D merasa } \\
\text { tidak berdaya } \\
\text { dengan } \\
\text { keadaannya } \\
\text { sejarang yang } \\
\text { tidak bisa bekerja } \\
\text { bingung } \\
\text { memikirkan } \\
\text { anak-anak yang } \\
\text { jauh merantau } \\
\text { menurut pasien, } \\
\text { dukungan } \\
\text { keluarga nomor } \\
\text { satu } \\
\text { - Ny.D berfikir ia } \\
\text { selalu } \\
\text { merepotkan } \\
\text { - suaminya bila } \\
\text { terlalu lama dalam } \\
\text { keadaan seperti ini } \\
\text { - merasa } \\
\text { Kasihan } \\
\text { kepada suami } \\
\text { yang harus } \\
\text { menjaga dan } \\
\text { - merawat pasien. }\end{array}$ & $\begin{array}{l}\text { - Merasa } \\
\text { khawatir dan } \\
\text { sedih kepada } \\
\text { suami yang } \\
\text { merawatnya } \\
\text { setiap hari } \\
\text { - Merasa } \\
\text { bersalah } \\
\text { karena } \\
\text { merasa } \\
\text { merepotkan } \\
\text { suami } \\
\text { - Merasa } \\
\text { bosan } \\
\text { dengan } \\
\text { keadaan } \\
\text { sekarang }\end{array}$ & $\begin{array}{l}\text { - Pusing } \\
\text { - Mual } \\
\text { - Mulut tampak } \\
\text { kering } \\
\text { - Sulit tidur } \\
\text { - Bahu terasa } \\
\text { tegang } \\
\text { - Konstipasi } \\
\text { - Tidak nafsu } \\
\text { makan } \\
\text { - Ny.D tampak } \\
\text { lemas } \\
\text { - Wajah Ny.D } \\
\text { tampak pucat } \\
\text { Pemeriksaan }\end{array}$ & $\begin{array}{l}\text { - Kontak mata } \\
\text { ada tapi tidak } \\
\text { bertahan } \\
\text { lama } \\
\text { - Volume } \\
\text { suara } \\
\text { mengecil } \\
\text { - Ny.D } \\
\text { tampak } \\
\text { gelisah }\end{array}$ & $\begin{array}{l}\text { - Hubungan } \\
\text { Ny.D dengan } \\
\text { suami baik } \\
\text { - Hubungan } \\
\text { Ny.D dengan } \\
\text { petugas } \\
\text { kesehatan } \\
\text { baik } \\
\text { - Ny. D tetap } \\
\text { mengikuti } \\
\text { program } \\
\text { pengobatan }\end{array}$ & $\begin{array}{l}\text { - Penampilan } \\
\text { peran tidak } \\
\text { efektif }\end{array}$ \\
\hline
\end{tabular}




\subsubsection{Sumber Koping}

\begin{tabular}{|c|c|c|c|c|c|}
\hline $\begin{array}{c}\text { DIAGNOSA } \\
\text { KEPERAWATAN }\end{array}$ & PERSONAL ABILITY & $\begin{array}{l}\text { SOSIAL } \\
\text { SUPPORT }\end{array}$ & $\begin{array}{l}\text { MATERIAL } \\
\text { ASSETS }\end{array}$ & $\begin{array}{l}\text { POSITIE } \\
\text { BELIEFS }\end{array}$ & TERAPI \\
\hline Ketidakberdayaan & $\begin{array}{l}\text { - } \text { Ny.D mampu } \\
\text { mengungkapkan } \\
\text { perasaan cemas } \\
\text { - Ny.D mengatakan bila } \\
\text { cemasnya memuncak } \\
\text { maka ia akan } \\
\text { mengambil air wudhu } \\
\text { dan sholat }\end{array}$ & 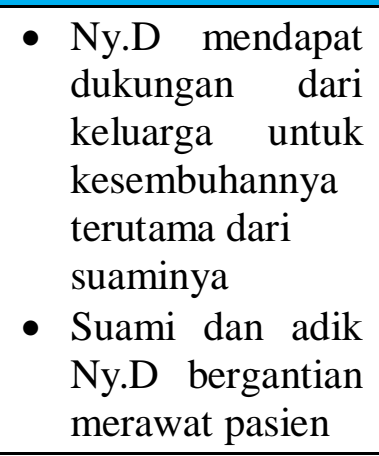 & $\begin{array}{l}\text { - Sosial ekonomi } \\
\text { Ny. D menengah } \\
\text { Pengobatan } \\
\text { ditanggung BPJS } \\
\text { - Jarak rumah } \\
\text { Ny.D dengan } \\
\text { tempat pelayanan } \\
\text { kesehatan lebih } \\
\text { kurang } 500 \text { meter }\end{array}$ & $\begin{array}{l}\text { - Ny.D percaya bahwa } \\
\text { petugas kesehatan } \\
\text { akan membantunya } \\
\text { - Ny.D berharap cepat } \\
\text { sembuh agar tidak } \\
\text { merepotkan } \\
\text { Suaminya }\end{array}$ & $\begin{array}{l}\text { Terapi spesialis: } \\
\text { - } \text { Relaksasi } \\
\text { progresif } \\
\text { - Psikoedukasi } \\
\text { keluarga } \\
\text { - Behavior } \\
\text { therapy } \\
\text { - Psikoedukasi } \\
\text { keluarga }\end{array}$ \\
\hline
\end{tabular}




\begin{tabular}{|c|c|c|}
\hline $\begin{array}{l}\text { Penampilan peran } \\
\text { tidak efektif }\end{array}$ & $\begin{array}{l}\text { - Ny.D dapat } \\
\text { menyebutkan } \\
\text { penyebab } \\
\text { penampilan peran } \\
\text { tidak efektif } \\
\text { - Ny.D } \\
\text { menganggap } \\
\text { suami tidak } \\
\text { mampu sebagai } \\
\text { pengganti akibat } \\
\text { kondisi yang } \\
\text { berubah }\end{array}$ & $\begin{array}{l}\text { - Ny.D selalu } \\
\text { berdoa untuk } \\
\text { kesembuhan } \\
\text { penyakitnya } \\
\text { - Ny.D yakin, bila ia } \\
\text { mengikuti petunjuk } \\
\text { dan saran dari } \\
\text { petugas kesehatan } \\
\text { maka ia akan cepat } \\
\text { sembuh suami } \\
\text { Ny.D yakin suami keluarga } \\
\text { dan supaya } \\
\text { mendukung } \\
\text { lekas sembuh } \\
\text { - Ny.D percaya bahwa } \\
\text { petugas kesehatan } \\
\text { akan membantunya } \\
\text { - Ny.D berharap } \\
\text { cepat sembuh agar } \\
\text { tidak merepotkan } \\
\text { suaminya }\end{array}$ \\
\hline
\end{tabular}




\begin{tabular}{|c|c|c|c|c|c|}
\hline Kurang pengetahuan & $\begin{array}{l}\text { - Ny.D mampu mengenal } \\
\text { dan menilai } \\
\text { Komplikasi dari } \\
\text { penyakitnya } \\
\text { - Ny.D mampu } \\
\text { melatih cara hidup } \\
\text { sehat }\end{array}$ & $\begin{array}{l}\text { - Ny.D mendapat } \\
\text { dukungan dari } \\
\text { keluarga untuk } \\
\text { kesembuhannya } \\
\text { terutama dari } \\
\text { suaminya } \\
\text { - Suami dan } \\
\text { keluarga Ny.A } \\
\text { bergantian } \\
\text { menjaga dan } \\
\text { mengunjungi } \\
\text { pasien } \\
\text { Tetangga Ny.A } \\
\text { dan teman di } \\
\text { tempat kerja } \\
\text { juga banyak } \\
\text { yang } \\
\text { mengunjungi } \\
\text { pasien }\end{array}$ & $\begin{array}{l}\text { - Sosial ekonomi } \\
\text { Ny.D menengah } \\
\text { - } \text { Ny.D tinggal di } \\
\text { rumah sendiri, } \\
\text { rumah } \\
\text { permanen } \\
\text { - Sarana dan } \\
\text { prasarana } \\
\text { tersedia } \\
\text { - } \text { Biaya } \\
\text { pengobatan } \\
\text { ditanggung oleh } \\
\text { asuransi BPJS } \\
\text { Jarak rumah Ny } \\
\text { A.Sdengan } \\
\text { tempat } \\
\text { pelayanan } \\
\text { kesehatan } \\
\text { (RSMM) lebih } \\
\text { kurang } \quad 500 \\
\text { meter }\end{array}$ & $\begin{array}{l}\text { - Ny.D percaya bahwa } \\
\text { petugas kesehatan } \\
\text { akan membantunya } \\
\text { - Ny.D berharap } \\
\text { cepat sembuh agar } \\
\text { tidak merepotkan } \\
\text { suaminya } \\
\text { - Ny.A selalu } \\
\text { berdoa untuk } \\
\text { kesembuhan } \\
\text { penyakitnya } \\
\text { Ny.A yakin, bila ia } \\
\text { mengikuti } \\
\text { petunjuk dan saran } \\
\text { dari petugas } \\
\text { kesehatan maka ia } \\
\text { akan cepat sembuh } \\
\text { - Ny.A yakin suami } \\
\text { dan keluarga } \\
\text { mendukung } \\
\text { supaya lekas } \\
\text { sembuh }\end{array}$ & $\begin{array}{l}\text { Terapi generalis: } \\
\text { - SP } \quad \text { 1-2 } \\
\quad \text { kurang } \\
\text { pengetahuan } \\
\text { Terapi spesialis: } \\
\text { Terapi suportif, } \\
\text { FPE }\end{array}$ \\
\hline
\end{tabular}




\subsubsection{Mekanisme Koping}

\begin{tabular}{|c|c|}
\hline $\begin{array}{l}\text { HAL YANG } \\
\text { DILAKUKAN }\end{array}$ & ANALISA \\
\hline $\begin{array}{l}\text { - Ny.D mengatakan bila ada masalah, maka ia akan membicarakan } \\
\text { dengan suami dan keluarga untuk mencari jalan keluarnya } \\
\text { - Bila sakit Ny.D berobat ke pelayanan kesehatan } \\
\text { - Ny.D taat menjalankan ibadah sesuai dengan keyakinannya } \\
\text { - Ny.D selalu berdoa kepada Allah SWT untuk kesembuhannya }\end{array}$ & $\begin{array}{l}\text { - Konstruktif: } \\
\checkmark \text { Ny.D mengatakan bila ada masalah, maka ia akan } \\
\text { membicarakan dengan suami dan keluarga untuk } \\
\text { mencari jalan keluarnya } \\
\checkmark \text { Bila sakit Ny.D berobat ke pelayanan kesehatan } \\
\checkmark \text { Ny.D taat menjalankan ibadah sesuai } \\
\text { dengan keyakinannya } \\
\checkmark \text { Ny.D selalu berdoa kepada Allah SWT } \\
\text { untuk kesembuhannya. }\end{array}$ \\
\hline & - Destruktif : - \\
\hline
\end{tabular}




\subsubsection{Status Mental}

\begin{tabular}{|l|l|}
\hline 1. Penampilan & Bersih, rapi, tidak tercium bau, Ny.D tampak lemas \\
\hline 2. Pembicaraan & Susah berbicara akibat dari kelumpuhan sebelah dari anggota tubuh (afasia ) \\
\hline 3. Aktivitas motoric & Tubuh sulit digerakkan \\
\hline 4. Interaksi selama wawancara & Cukup kooperatif, meskipun afasia \\
\hline 5. Alam perasaan & Sedih, merasa cemas ,takut dan bingung mengenai kondisi penyakit, suami dan anak-anaknya \\
\hline 6. Afek & Datar \\
\hline 7. Persepsi & Ny.D mengalami gangguan dalam proses sensori-persepsi \\
\hline 8. Isi piker & Mengalami masalah karena sebagian memori terlupakan \\
\hline 9. Proses piker & masalah karena sebagian memori terlupakan \\
\hline 10. Tingkat kesadaran & Ny.D dapat menyebutkan kembali nama suami \\
\hline 11. Daya ingat & Ny.D tidak dapat mengingat beberapa kejadian dalam hidupnya \\
\hline 12. Kemampuan berhitung & Kemampuan berhitung cukup baik \\
\hline 13. Penilaian & Ny.D belum mampu menyebutkan bagaimana caranya agar Ny.D lekas sembuh \\
\hline 14. Daya tilik diri & $\begin{array}{l}\text { Ny.D menyadari bahwa saat ini ia sdang sakit, Ny.D hanya bisa berdoa supaya lekas sembuh agar } \\
\text { tidak terus merepotkan suaminya. Ny.D menyadari ia memiliki suami, anak-anak dan keluarga } \\
\text { yang menyayanginya dan mendukung kesembuhannya }\end{array}$ \\
\hline
\end{tabular}


Kesimpulan : Mental Status Examination (MSE) tidak ada masalah gangguan jiwa, gangguan Ny.D lebih kepada Gangguan Mental Emosional (GME/Psikososial)

\subsection{Diagnosa Dan Terapi}

\section{DIAGNOSA KEPERAWATAN DAN TERAPI KEPERAWATAN}

DIAGNOSA MEDIS

1. Ansietas

Sp1: mendiskusikan penyebab,terjadinya prosesterjadi, tanda gejala,akibat

$\mathrm{Sp} 2$ :melatih teknik releksasi fisik

Sp3:melatih mengatasi ansietas dengan distraksi dan hipnotis lima

Sp4 : melatih mengatasi ansietas memalui kegiatan spritual

Terapi Spesialis: TS, PMR, Logo ACT

2. Penampilan peran tidak efektif

Terapi perilaku

3. Kurang pengetahuan

Terapi suportif, FPE 


\subsection{Implementasi Tindakan Kperawatan Dan Evaluasi}

\begin{tabular}{|c|c|}
\hline IMPLEMENTASI TINDAKAN KEPERAWATAN & EVALUASI \\
\hline $\begin{array}{l}\text { Tanggal : } 07 \text { Oktober } 2021 \\
\text { Jam : } 10.00 \text { wib } \\
\text { a. Kaji tanda dan gejala ansietas dan kemampuan klien mengurangi } \\
\text { kecemasan } \\
\text { b. Jelaskan tanda dan gejala, penyebab dan akibat dari kecemasan } \\
\text { c. Latihan cara mengatasi kecemasan : } \\
\text { 1) Teknik relaksasi napas dalam } \\
\text { 2) Distraksi : bercakap-cakap hal positif } \\
\text { 3) Hipnotis } 5 \text { jari fokus padahal-hal yang positif } \\
\text { d. Bantu klien melakukan latihan sesuai dengan jadwal kegiatan. }\end{array}$ & \begin{tabular}{|ll} 
S : & \\
& Klien mengatakan : merasa lebih tenang tetapi \\
& belum sepenuhnya cemasnya hilang \\
& - \\
& Klien mengatakan ia mampu mengindentifikasi \\
& situasi yang mencetus ansietas \\
O : & \\
- & Klien tampak rileks dan tidak gelisah lagi \\
- & Klen mampu menjelaskan kembali penjelasan \\
& yang sudah diberikan \\
A : & Ansietas (+) \\
P : & \\
- & Evaluasi SP-1 dan SP-2 \\
- & Latihan cara mengatasi kecemasan : \\
& - Teknik relaksasi napas dalam \\
& - Distraksi : bercakap-cakap hal positif \\
& - Hipnotis 5 jari fokus padahal-hal yang positif \\
- & Bantu klien melakukan latihan sesuai dengan jadwal \\
& kegiatan
\end{tabular} \\
\hline
\end{tabular}




\begin{tabular}{|c|c|}
\hline $\begin{array}{l}\text { Tanggal : } 08 \text { Oktober } 2021 \\
\text { Jam : } 10.00 \text { wib } \\
\text { a. Latihan cara mengatasi kecemasan : } \\
\quad \text { - Teknik relaksasi napas dalam } \\
\text { - Distraksi : bercakap-cakap hal positif } \\
\text { - Hipnotis } 5 \text { jari fokus padahal-hal yang positif } \\
\text { b. Bantu klien melakukan latihan sesuai dengan jadwal kegiatan. }\end{array}$ & 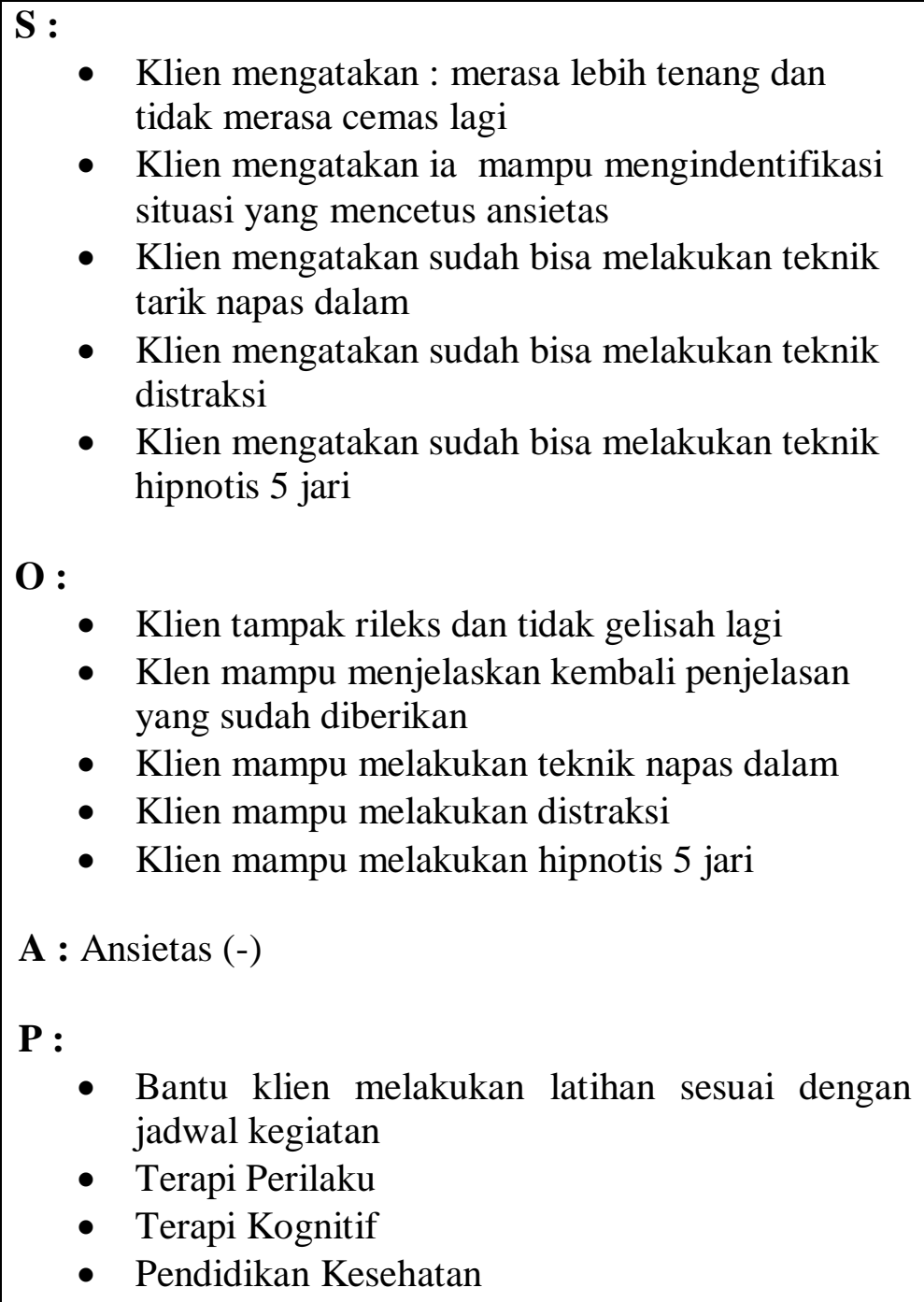 \\
\hline
\end{tabular}




\section{BAB 4 PEMBAHASAN}

Pada pembahasan ini penulis membahas tentang kesenjangan yang ditemukan antara teori dengan kasus yang penulis buat, pada pembahasan ini penulis menganalisa tentang hambatan yang ditemukan pada saat penulis melakukan asuhan keperawatan pada klien. Pada tahap pengkajian ditemukan adanya beberapa kesenjangan diantaranya respon perilaku. Pada respon perilaku menurut teori tanda gejalanya adalah rasa terbakar di jantung, sering kencing dan kulit terasa panas, sedangkan pada kasus adalah klien tidak menunjukkan respon perlaku seperti pada teori. Hal ini disebabkan karena kecemasan yang dialami klien masih tahap sedang.

Pada tahap diagnosa dan perencanaan tidak ditemukan kesenjangan antara teori dan kasus dimana diagnosa yang diangkat adalah kecemasan, penampilan peran tidak efektif dan kurang pengetahuan sama halnya dengan intervensi, rencana asuhan keperawatan pada Ny. A dimulai setelah data terkumpul yang didapat dari hasil pengkajian. Tindakan yang diberikan pun yaitu terapi dan pendidikan kesehatan. Pembahasan pada implementasi penulis melaksanakan tindakan keperawatan sesuai dengan rencana yang sudah ditetapkan. Sebelumnya penulis melakukan kontrak waktu kepada pasien untuk melakukan implementasi, selama tahap implementasi tidak ada hambatan dan klien kooperatif dalam mengikuti terapinya.

Pada tahap evaluasi penulis hanya dapat melaksanakan diagnosa keperawatan yang pertama saja. Pada evaluasi yang diharapkan adalah :

a. Membina hubungan saling percaya

b. Mengenali dan mengekspresikan emosinya

c. Mampu mengenal ansietas

d. Mampu mengatasi ansietas melalui teknik releksasi

e. Mampu mengatasi ansietas dengan distraksi

f. Mampu mengatasi ansietas melalui hipnotis lima jari

g. Mampu mengatasi ansietas melalui kegiatan spiritual 


\section{BAB 5}

\section{PENUTUP}

\subsection{Kesimpulan}

Berdasarkan konsep asuhan keperawatan yang telah disusun dan dilaksanakan kepada Ny.A dimiliki dari pengkajian, rumusan masalah, perencanaan, pelaksanaan hingga evaluasi didapat hasil bahwa Ny.A dengan keluhan utama cemas akan Penyakit diabetes melitus sehingga tidak mampu melakukan aktivitas seperti biasanya Data objektif yaitu klien tampak Badan lemas,kesemutan, gatal, gemetaran pusing luka yang lama sembuh, Kadar glukosa darah tinggi Dari masalah masalah diatas maka diperoleh prioritas

masalah yang diangkat adalah tentang kebutuhan rasa aman nyaman yang berfokus pada cemas. Kemudian diberikan intervensi secara konsep yaitu terapi teknik relaksasi napas dalam, terapi distraksi, hipnotis lima jari dan pendidikan kesehatan. Dari hasil implementasi ada beberapa intervensi yang berhasil teratasi seperti klien mengatakan sudah lebih tenang dan cemas nya sedikit berkurang dan mampu mengenali gejala, tanda, penyebab dan akibat dari kecemasan. Sedangkan klien masih bingung dalam melakukan terapi hipnotis lima jari maka intervensi dilanjutkan.

\subsection{Saran}

Diharapkan bagi perawat selalu berkoordinasi dengan tenaga kesehatan lainnya dalam memberikan asuhan keperawatan agar lebih maksimal terkusus pada klien dengan kecemasan pada pasien diabetes melitus. 


\section{DAFTAR PUSTAKA}

1. Azari, A. A., \& Zururi, M. I. (2021). Faktor-Faktor Yang Berhubungan Dengan Depresi Pada Lansia. Medical Jurnal Of Al Qodiri, 6(2), 66-72 https://doi.org/10.52264/jurnal_stikesalqodiri.v6i2.94.

2. Jannah, N., \& Putri, Y. S. E. (2015). Penerapan teknik berpikir positif dan afirmasi positif pada klien ketidakberdayaan dengan gagal jantung kongestif. Jurnal Keperawatan Jiwa (JKJ): Persatuan Perawat Nasional Indonesia, 3(2), 30-39 https://doi.org/10.26714/jkj.3.2.2015.30-39

3. Maruhashi, T., \& Higashi, Y. (2021). Pathophysiological Association between Diabetes Mellitus and Endothelial Dysfunction. Antioxidants, 10(8), 1306 https://doi.org/10.3390/antiox10081306.

4. Nuraliyah, S., \& Burmanajaya, B. (2019). Mekanisme Koping dan Respon Ketidakberdayaan pada Pasien Stroke https://doi.org/10.34011/juriskesbdg.v11i1.227.

5. Pardede, J. A. (2020). Konsep Ketidakberdayaan.

6. Pardede, J. A. (2020). Terapi Keluarga.

7. Pardede, J. A. (2020). Standar Asuhan Keperawatan Jiwa Dengan Masalah Kecemasan.

8. Pardede, J. A., Hasibuan, E. K., \& Hondro, H. S. (2020). Perilaku Caring Perawat Dengan Koping Dan Kecemasan Keluarga. Indonesian Journal of Nursing Sciences and Practice, 3(1), 14-22. https://doi.org/10.24853/ijnsp.v3i1.14-22 10.

9. Pardede, J. A., Sitepu, S. F. A., \& Saragih, M. (2018). The Influence of Deep Breath Relaxation Techniques and Five-Finger Hypnotic Therapy on Preoperative Patient Anxiety. Journal of Psychiatry, 3(1), 1-8.

10. PPNI (2018). Standar Intervensi Keperawatan Indonesia: Definisi dan Tindakan Keperawatan, Edisi 1 Jakarta : DPP PPNI.

11. PPNI (2018). Standar Luaran Keperawatan Indonesia: Definisi dan Kriteria HasilKeperawatan, Edisi 1 Jakarta : DPP PPNI.

12. PPNI. (2016). Standar Diagnosa Keperawatan Indonesia: Definisi dan Indikator Diagnostik, Edisi 1. Jakarta : DPP PPNI. 
13. Prayogo, D., \& Rehulina, M. (2014). Hubungan antara adversity dan ketidakberdayaan yang dipelajari pada anak yang berhadapan dengan hukum $(\mathrm{ABH})$ di Rumah tahanan surabaya. Jurnal Psikologi Industri dan Organisasi, 3(2), 108-116.

14. Keliat, B. A., \& Wardhani, I. Y. (2019). Hubungan Kemampuan Mengubah Pikiran Negatif Dengan Depresi Dan Ketidakberdayaan Pada Klien Stroke. Al-Asalmiya Nursing: Journal of Nursing Sciences, 8(1), 17-23. https://jurnal.stikes-alinsyirah.ac.id/index.php/keperawatan/article/view/143

15. Regina, C. C., Mu'ti, A., \& Fitriany, E. (2021). Systematic Review Tentang Pengaruh Obesitas Terhadap Kejadian Komplikasi Diabetes Melitus Tipe Dua. Verdure: Health Science Journal, 3(1), 8-17.

16. Riskesdas .(2018). Kementrian Kesehatan Republik Indonesia, Riset Kesehatan Dasar 2018 https://doi.org/10.22435/jpppk.v3i1.1882.

17. Sarani, D. (2021). Asuhan Keperawatan Pada Pasien Stroke Non Hemoragik Dengan Masalah Keperawatan Ketidakberdayaan (Doctoral dissertation, Universitas Muhammadiyah Ponorogo).

18. Sari, I. P., \& Effendi, M. (2020). Efektifitas Senam Diabetes Terhadap Kadar Gula Darah Pada Pasien Diabetes Mellitus di Lamongan. Indonesian Journal for Health Sciences, 4(1), 45-50.

19. Saviqoh, I. D., \& Hasneli, Y. (2021). Analisis Pola Hidup Dan Dukungan Keluarga Pada Pasien Diabetes Melitus Tipe 2 Di Wilayah Kerja Puskesmas Payung Sekaki. Health Care: Jurnal Kesehatan,10(1), 181-193 https://doi.org/10.36763/healthcare.v10i1.116.

20. Pardede, J. A., Hutajulu, J., \& Pasaribu, P. E. (2020). Harga Diri dengan Depresi Pasien Hiv/aids. Jurnal Media Keperawatan: Politeknik Kesehatan Makassar, 11(01). : https://doi.org/10.32382/jmk.v11i1.1538 8.

21. Pardede, J. A., Keliat, B. A., Damanik, R. K., \& Gulo, A. R. B. (2020). Optimalization of Coping Nurses to Overcoming Anxiety in the Pandemic of Covid-19 in Era New Normal. Jurnal Peduli Masyarakat, 2(3), 105-112. https://doi.org/10.37287/jpm.v2i3.128 https://doi.org/10.37287/jpm.v2i3.128

22. Ummah, T., Wardani, I. Y., \& Hargiana, G. (2018). Asuhan Keperawatan Psikososial: Ketidakberdayaan Pada Klien Dengan Gagal Jantung. Jurnal 
Keperawatan, 10(2), 138-146

https://doi.org/10.32583/keperawatan.10.2.2018.138-146.

23. Wahyudi, U., \& Burnamajaya, B. (2020). Konsep Diri dan Ketidakberdayaan Berhubungan dengan Risiko Bunuh Diri pada Remaja yang Mengalami Bullying. Jurnal Keperawatan Jiwa (JKJ): Persatuan Perawat Nasional Indonesia, 8(1), 1-8 https://doi.org/10.26714/jkj.8.1.2020.1-8.

24. Yusuf, R. S., \& Wardan, I. Y. (2015). Analisis Praktik Klinik Keperawatan Kesehatan Masyarakat Perkotaan Ketidakberdayaan Pada Klien Diabetes Melitus Tipe Ii Di Ruang Antasena Rumah Sakit Dr. H. Marzoeki Mahdi Bogor. Jurnal Keperawatan Jiwa (JKJ): Persatuan Perawat Nasional Indonesia, 3(2), 61-69 https://doi.org/10.26714/jkj.3.2.2015.61-69.

25. Zai, Y., Bu'ulolo, K., Fajariani, N., Hulu, Y., Gulo, R. E., \& Nurhayati, E. L. (2020). Hubungan Dukungan Keluarga dengan Tingkat Harga Diri pada Penderita Stroke di Rumah Sakit Umum Royal Prima Medan. Jurnal Riset Hesti Medan Akper Kesdam I/BB Medan, 4(2), 66-73 https://doi.org/10.34008/jurhesti.v4i2.137.

26. Zaini, M. (2019). Asuhan keperawatan Jiwa Masalah Psikososial Di Pelayanan Klinis dan Komunitas. Deepublish : Yogyakarta.

27. Pardede, J. A., Hulu, D. E. S. P., \& Sirait, A. (2021). Tingkat Kecemasan Menurun Setelah Diberikan Terapi Hipnotis Lima Jari pada Pasien Preoperatif. Jurnal Keperawatan, 13(1), 265-272. 